\title{
A case of very delayed surgical site infection after instrumented spine surgery
}

\section{Dobran Mauro, Nasi Davide, Paracino Riccardo, Bizzocchi Gianluca, Marini Alessandra, and Scerrati Massimo}

Department of Neurosurgery, Università Politecnica delle Marche, Umberto I General Hospital, Ancona, Italy

\section{CASE STUDY}

Please cite this paper as: Dobran $M$, Nasi D, Paracino $R$, Bizzocchi G, Marini A, Scerrati M. A case of very delayed surgical site infection after instrumented spine surgery. AMJ 2018;11(3):168-170.

https://doi.org/10.21767/AMJ.2018.3294

Corresponding Author:

Dobran Mauro

Department of Neurosurgery, Università Politecnica delle Marche, Umberto I General Hospital, Ancona, Italy

Email: dobran@libero.it

\section{ABSTRACT}

This is a case of a 69-year-old obese woman treated with posterior spinal stabilization for lumbar degenerative stenosis who developed delayed and persistent surgical site infection sustained by Bacteriodes fragilis. This microorganism is characterized by slow growth and resistance to antimicrobial agents. The patient underwent a surgical treatment with debridement of the surgical wound without hardware removal. After fourteen months the patient had a recurrence of low back pain, low-grade fever and dehiscence of surgical wound with the need of hardware removal. The intra-operative culture was positive for the same microrganism, than she healed with target antibiotic therapy.

\section{Key Words}

Delayed infection, Bacteriodes fragilis, spine

\section{Implications for Practice:}

\section{What is known about this subject?}

The presence of surgical site infection increases morbidity and mortality in operated patients. Proper medical e/o surgical treatment allows the recovery.

\section{What new information is offered in this case study?}

Bacteriodes fragilis is difficult to isolate and treatment is complicated by slow growth, resistance to antimicrobial agents and polymicrobial synergistic nature of the infection.

3. What are the implications for research, policy, or practice?

Removal of the hardware in case of persistent and delayed $\mathrm{SSI}$ is safe if there are signs of vertebral fusion with a complete recovery.

\section{Background}

Post-operative surgical site infections (SSI) are serious complications in instrumented spine surgery ${ }^{1-8}$ despite the diffusion of minimally invasive techniques. ${ }^{4}$ The treatment of delayed SSI remains controversial and, despite the earlyonset SSI, are less frequent. These infections are associated with poor outcome and, if not properly treated, patient's death. In case of delayed infections the culture could be negative despite an active infection. Bacteroides fragilis is difficult to eradicate and in case of subsequent negative culture, the monitoring of the patient must be maintained for a long time. This is a case report of an instrumented patient with delayed and persistent surgical site infection sustained by Bacteroides fragilis.

\section{Case details}

This is a case of a 69-year-old obese woman treated with posterior L2-S1 spinal stabilization and L3-L5 laminectomy for lumbar degenerative stenosis. After two weeks from surgery appeared fever $\left(38^{\circ} \mathrm{C}\right)$ and dehiscence of the surgical wound with serum-purulent material leak. At admission contrast Computer Tomography (CT) scan showed an abscess of the paravertebral muscles without signs of vertebral arthrodesis (Figure $1 \mathrm{~A}$ and $\mathrm{B}$ ). The laboratory exams revealed high level of ESR, CRP and procalcitonine (Table 1) without leucocytosis. Antibiotic therapy with vancomycin (2g/day) and piperacillintazobactam (13.5g/day) started immediately and the 
patient underwent a second surgical treatment with debridement of the surgical wound without hardware removal. Intraoperative and pre-operative culture documented an infection supported by Enterococcus faecalis, Bacterioides fragilis and Prevotella bivia. Intravenus antibiotic target therapy, according with the minimal inhibitory concentration (MIC) testing, started with vancomycin (2g/day) and meropenem (3g/day) for two weeks. After three weeks the fever disappeared, procalcitonin, ESR and CRP normalized with complete healing of the wound (Table 1). The patient was discharged with amoxicillin $1 \mathrm{~g} \times 3$ therapy prolonged for six weeks. The twomonth follow-up contrast CT scan and blood exams confirmed the resolution of the surgical site infection, with clinical recovery.

Fourteen months later the patient had a recurrence of low back pain, low-grade fever $\left(37.4^{\circ} \mathrm{C}\right)$ and dehiscence of surgical wound with leak of purulent material. The laboratory tests documented the increase of ESR (Table 1) and vertebral contrast CT scan showed a new paravertebral muscles abscess extended to psoas muscles with signs of vertebral fusion. Wound swab culture was negative for bacterial growth. Intravenous antibiotic therapy started with ceftazidime $(6 \mathrm{~g} /$ day) and vancomycin $(2 \mathrm{~g} /$ day). Two days after the patient underwent a revision surgery with removal of the hardware and drainage of the abscess. The intra-operative culture was positive for the pre-exist Bacteriodes fragilis. Few days after surgery laboratory tests documented the reduction of the leukocyte count and the normalization of ESR value (see Table 1).

The patient was discharged with amoxicillin $1 \mathrm{~g} \times 3$ antibiotic therapy for 6 weeks. The one-month follow-up contrast MRI showed the healing of the surgical site infection. After 6 months wound was healed without infections signs.

\section{Discussion}

Surgical site infection after instrumented spine surgery is a challenging pathology for diagnosis and treatment. ${ }^{1-4}$ There are many peri-operative risk factors of SSI documented in literature, such as obesity ${ }^{7}$ and the described patient was obese with $\mathrm{BMI}>30$.

Although early surgical site infections represent the most common type of infections after instrumented spine surgery, sometimes there is a long latency for the onset of symptoms. The median of infection symptoms appearance are about 3-11 months according to literature. ${ }^{1,5,6}$

Delayed infections may remain unacknowledged even for long time before the correct diagnosis is reached. ${ }^{1}$ Symptoms are usually aspecific with local pain, fever and signs of inflammation of the surgical wound. ${ }^{1-5}$

In $80-90 \%$ of the cases there is a concomitant increases in ESR values at the same time of the low back pain's recurrence. ${ }^{6}$ For diagnosis of delayed SSI, often the surgical wound swab is negative. Indeed, microorganisms tend to form an exopolysaccharide matrix (a glycosal matrix) close to the hardware, and they are present with low concentration into the host-matrix interface, where the wound swab is usually done. ${ }^{1,4}$ The false negativity of wound swab in delayed SSI is also determined by the different microorganisms involved, that exhibit a lower virulence compared to the bacteria involved in early SSI. ${ }^{1-5}$ Bacteorides fragilis has been described in literature as a low-virulence microorganism and able to form biofilm; ${ }^{7,8}$ however are described only few cases of delayed vertebral infections caused by this organism. ${ }^{5,6}$ In the literature, the delayed SSI are often sustained by Staphylococcus aureus, Staphylococcus epidermidis ${ }^{1-4,7}$ and Propionibacterium acnes. ${ }^{1-4}$ The etiopathogenetic mechanism has not yet been clearly defined, but there are two possibilities: contamination of microorganisms during surgery or in the postoperative period and haematogenous spread. ${ }^{5,6}$ Bacteriodes species are anaerobic bacteria that are predominant components of the bacterial florae of mucous membranes and are common cause of endogenous infections.

Secondary infections by haematogenous coming from an oropharyngeal or abdominal site constitute the other main source. ${ }^{7,8}$ In our patient we supposed the haematogenous spreading from an oropharyngeal or abdominal site because the patient had not any concomitant loco-regional infection. For vertebral location, to the best of our knowledge, there are only four cases described in literature. No data is available regarding the optimal antibiotic therapy of this infection, either regarding the route of administration or the duration of therapy. On the basis of MIC, we used Vancomycin and Meropenem for two weeks followed by Ceftazidime, vancomycin and Amoxicillin for others 4 weeks. About the prevention of these infections, the selection of patient for vertebral instrumented surgery must be careful: in case of concomitant oropharyngeal or abdominal infections, surgery must be delayed. Bacteriodes are difficult to isolate and treatment is complicated by slow growth, resistance to antimicrobial agents and polymicrobial synergistic nature of the infection. The slow growth of bacteriodes may explains the delayed infection of the described case. ${ }^{5,6}$ Finally, removal of the hardware in 
case of delayed SSI could be safe if there are signs of vertebral fusion, so this reduces the risk of pseudoarthrosis and deformity. ${ }^{1-4,7,8}$ In all cases this is the last option after a prolonged target therapy. ${ }^{1-4,7,8}$

\section{Conclusion}

Delayed SSI is difficult to diagnose and are sustained by slow growth microrganisms. Bacteroides fragilis is difficult to eradicate and in case of subsequent negative culture, the monitoring of the patient must be maintained for a long time. The removal of the hardware is the last option after a properly antibiotic target therapy based on culture wound swab or blood. The presence of fusion allows the hardware removal without risks for spinal stability.

\section{References}

1. Dennis S, Meredith, Christopher K, et al. Posteoperative infections of the lumbar spine: presentation and management. Int Orthop. 2012;36:439-444.

2. Dobran M, Marini A, Gladi M, et al. Deep spinal infection in instrumented spinal surgery: diagnostic factors and therapy. G Chir. 2017;38(3):124-129.

3. Dobran M, Marini A, Nasi D, et al. Risk factors of surgical site infections in instrumented spine surgery. Surg Neurol Int. 2017;8:212.

4. lacoangeli $M$, Nocchi $N$, Nasi $D$, et al. Minimally Invasive Supraorbital Key-hole Approach for the Treatment of Anterior Cranial Fossa Meningiomas. Neurol Med Chir (Tokyo). 2016;56(4):180-5.

5. Pumbwe L, Skilbeck CA, Wexler HM. Presence of Quorum-sensing Systems Associated with Multidrug Resistance and Biofilm Formation in Bacteroides fragilis. Microb Ecol. 2008;56(3):412-419.

6. Kierzkowska M, Pedzisz P, Babiak I, et al. Orthopedic infections caused by obligatory anaerobic Gram-negative rods: report of two cases. Med Microbiol Immunol. 2017;206(5):363-366.

7. Dobran M, Mancini F, Nasi D, et al. A case of deep infection after instrumentation in dorsal spinal surgery: the management with antibiotics and negative wound pressure without removal of fixation. BMJ Case Reports. 2017;2017:bcr2017220792.

8. Dobran $M$, lacoangeli $M$, Nasi $D$, et al. Posterior Titanium Screw Fixation without Debridement of Infected Tissue for the Treatment of Thoracolumbar Spontaneous Pyogenic Spondylodiscitis. Asian Spine J. 2016;10(3):465-471.

\section{PEER REVIEW}

Not commissioned. Externally peer reviewed.

\section{CONFLICTS OF INTEREST}

The authors declare that they have no competing interests.

\section{PATIENT CONSENT}

The authors, Dobran $M$, Nasi D, Paracino R, Bizzocchi G, Marini A, Scerrati $M$, declare that:

1. They have obtained written, informed consent for the publication of the details relating to the patient(s) in this report.

2. All possible steps have been taken to safeguard the identity of the patient(s).

3. This submission is compliant with the requirements of local research ethics committees.

Table 1: Summary synopsis of laboratory tests

\begin{tabular}{|c|c|c|c|c|}
\hline & $\begin{array}{c}\text { First } \\
\text { admission }\end{array}$ & $\begin{array}{c}\text { After } \\
\text { treatment } \\
\text { (three } \\
\text { weeks } \\
\text { later) }\end{array}$ & $\begin{array}{c}\text { Second } \\
\text { admission } \\
\text { (fourteen } \\
\text { months } \\
\text { later) }\end{array}$ & $\begin{array}{c}\text { After } \\
\text { treatment } \\
\text { (few day } \\
\text { after } \\
\text { surgery) }\end{array}$ \\
\hline Culture & $\begin{array}{c}\text { Enterococcus } \\
\text { faecalis, } \\
\text { Bacterioides } \\
\text { fragilis } \\
\text { Prevotella } \\
\text { bivia }\end{array}$ & $/$ & $\begin{array}{c}\text { Bacteriodes } \\
\text { fragilis }\end{array}$ & $/$ \\
\hline $\begin{array}{c}\text { CRP } \\
\text { (mg/d) }\end{array}$ & 3.5 & 0.4 & 9.2 & 0.3 \\
\hline $\begin{array}{c}\text { ESR } \\
\text { (mm/h) }\end{array}$ & 80 & 28 & 64 & 25 \\
\hline $\begin{array}{c}\text { Pro- } \\
\text { calcitonin } \\
\text { (ng/ml) }\end{array}$ & 0.07 & 0.04 & 0.10 & 0.03 \\
\hline $\begin{array}{c}\text { WBCs } \\
\text { (10 } \mathbf{3} / \mathbf{l})\end{array}$ & 8.35 & 8 & 23 & 10 \\
\hline Fever (C $\mathbf{C}^{\circ}$ & 38 & 36.4 & 37.4 & 36.5 \\
\hline
\end{tabular}

Figure 1AB: The Figure 1A showed a sagittal CT scan image at admission depicting the anaerobic infection with gas collection in the surgical site. The Figure 1B showed a sagittal CT scan before the discharge demonstrating the resolution of anaerobic infection

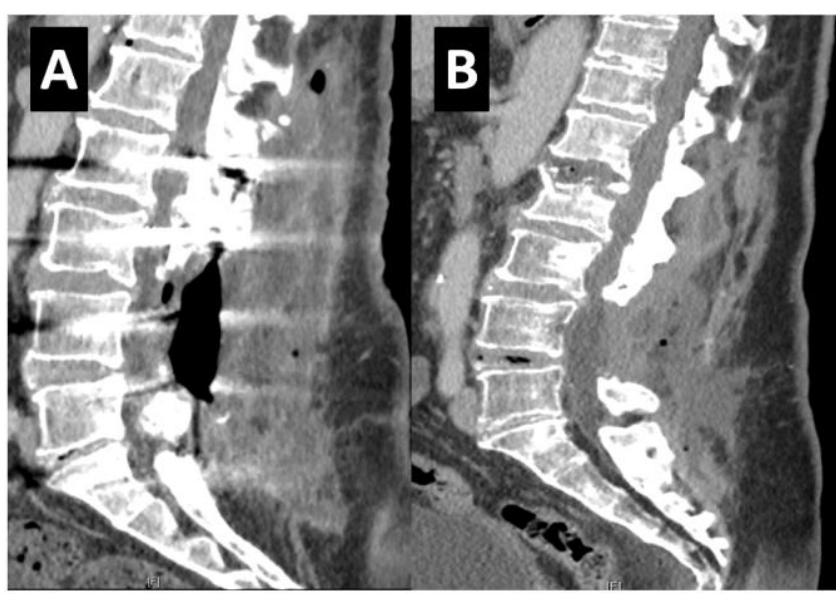

